\title{
Dexamethasone inhibits stemness maintenance and enhances chemosensitivity of hepatocellular carcinoma stem cells by inducing deSUMOylation of HIF-1 $\alpha$ and Oct4
}

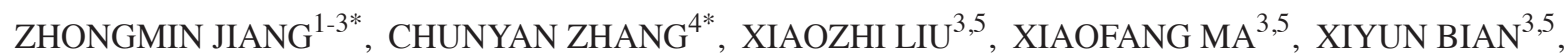 \\ XIAOLIN XIAO ${ }^{3,5}$, RUI GAO ${ }^{3,6}$, YAJING SUN ${ }^{2}$, WENHAN WU ${ }^{3,7,8}$ and PO ZHAO ${ }^{1}$ \\ ${ }^{1}$ Department of Pathology, Chinese People's Liberation Army (PLA) General Hospital, Beijing 100853; \\ ${ }^{2}$ Department of Pathology; ${ }^{3}$ Tianjin Key Laboratory of Epigenetics for Organ Development in Preterm Infants, The \\ Fifth Central Hospital of Tianjin, Tianjin 300450; ${ }^{4}$ Department of Pharmacy, Binhai New Area Hospital of Traditional \\ Chinese Medicine, Tianjin 300450; ${ }^{5}$ Central Laboratory; ${ }^{6}$ Department of Pharmacy, The Fifth Central Hospital \\ of Tianjin, Tianjin 300450; ${ }^{7}$ Department of General Surgery, Peking University First Hospital, Beijing 100031; \\ ${ }^{8}$ Department of General Surgery, The Fifth Central Hospital of Tianjin, Tianjin 300450, P.R. China
}

Received March 9, 2020; Accepted June 25, 2020

DOI: 10.3892/ijo.2020.5097

\begin{abstract}
It has been controversial whether patients with hepatocellular carcinoma (HCC) should receive glucocorticoid therapy during chemotherapy. Recent studies have demonstrated that glucocorticoids increase the therapeutic sensitivity of tumors to some chemotherapeutic drugs, but the specific mechanism remains unclear. In the present study, dexamethasone (Dex) was used to treat HCC stem cells. The results demonstrated that Dex reduced stemness maintenance and self-renewal of HCC stem cells, promoted epithelial-to-mesenchymal transition, inhibited migration and angiogenesis and, more importantly, increased cell sensitivity to the herpes simplex virus thymidine kinase/ganciclovir drug system in vitro and in vivo. Further mechanistic analyses demonstrated that Dex inhibited small ubiquitin-like modifier (SUMO) modification of several proteins in HCC stem cells, including hypoxia-inducible factor (HIF)-1 $\alpha$, an important hypoxia tolerance protein, and octamer-binding transcription
\end{abstract}

Correspondence to: Dr WenHan Wu, Department of General Surgery, Peking University First Hospital, 8 Xishku Street, Xicheng, Beijing 100031, P.R. China

E-mail:wuwenhan88@126.com

Dr Po Zhao, Department of Pathology, Chinese People's Liberation Army (PLA) General Hospital, 28 Fuxing Road, Beijing 100853, P.R. China

Email: zhaopo301@163.com

*Contributed equally

Key words: hepatocellular carcinoma, cancer stem cells, glucocorticoids, SUMOylation, herpes simplex virus 1 thymidine kinase/ganciclovir, hypoxia inducible factor- $1 \alpha$, octamer-binding transcription factor 4 factor 4 (Oct4), a crucial stemness maintenance protein. Inducing deSUMOylation of HIF-1 $\alpha$ and Oct4 reduced their accumulation in the nucleus, thereby inhibiting tumor angiogenesis and stemness maintenance. These findings provide a new perspective to the study of the mechanism underlying the anti-hepatocarcinogenesis effects of Dex. Due to the few side effects of glucocorticoids at low doses and their anti-inflammatory effects, the appropriate combination of glucocorticoids and chemotherapeutic drugs is expected to improve the survival of $\mathrm{HCC}$ patients and their prognosis.

\section{Introduction}

Hepatocellular carcinoma (HCC) is a primary liver cancer with a high mortality rate (1). In recent years, the incidence of liver cancer has not only increased, but also exhibits a tendency to occur in young individuals (2). Due to the strong compensatory function of the liver and the structural features of blood supply, liver tumors grow rapidly and are prone to metastasis (3). Therefore, these tumors are clinically diagnosed mostly during the mid and late stages of the disease, when the opportunity for surgical resection has been missed and the prognosis is poor. Surgical resection and liver transplantation are the main treatment methods for HCC (4), but intrahepatic metastasis and recurrence after surgery adversely affect the prognosis of HCC patients. Liver transplantation is often limited by a shortage of liver donors. Therefore, it is crucial to explore new methods to treat HCC based on traditional surgery, chemotherapy, radiotherapy, and other treatment strategies.

In recent years, there have been several reports on the development of new delivery systems for traditional chemotherapeutic drugs, such as cytotoxic drugs, new drugs for gene and molecular targets, and their various combinations $(5,6)$. However, due to the resistance of a small proportion of HCC stem cells against chemotherapeutic drugs, almost all currently investigated drugs have failed. Glucocorticoids are a type of anti-inflammatory drug that is widely used in the 
clinical setting to relieve symptoms in patients with advanced liver cancer, and have demonstrated certain therapeutic effects (7-9). However, to date, the therapeutic effect and synergistic mechanism of action of glucocorticoids combined with chemotherapeutic drugs for the treatment of patients with HCC remain unclear.

Accumulating studies have demonstrated that hypoxia-inducible factor (HIF)- $1 \alpha$ increases the tolerance of tumor stem cells to a hypoxic microenvironment by upregulating the expression of vascular endothelial growth factor, which is considered to be one of the major mechanisms of chemotherapy resistance in cancer stem cells (10-12). The persistent and stable presence of HIF-1 $\alpha$ in the cytoplasm under hypoxic conditions depends on its degree of conjugate binding to small ubiquitin-like modifier (SUMO) $(13,14)$. Similarly, the function of Oct4, a crucial stemness maintenance protein, is also dependent on SUMO modification $(15,16)$. SUMO4 is hardly expressed in hepatocytes (17) and the SUMO modification caused by SUMO2 and SUMO3 mainly occurs when cells respond to acute stress (18). Therefore, in the present study, only SUMO1 was assessed in order to analyze the effects of glucocorticoids on the stemness maintenance potential of HCC stem cells and the mechanism of chemotherapy resistance from the perspective of SUMOylation of these two important proteins, and to provide new targeted treatment options for HCC stem cells.

\section{Materials and methods}

HCC stem cell sorting. The human-derived HCC cell line Hep3B was purchased from the American Type Culture Collection. The culture medium was DMEM supplemented with $10 \% \mathrm{FBS}, 100 \mathrm{U} / \mathrm{ml}$ penicillin and $100 \mu \mathrm{g} / \mathrm{ml}$ streptomycin (all from Gibco; Thermo Fisher Scientific, Inc.). The cells were cultured at $37^{\circ} \mathrm{C}$ with $5 \% \mathrm{CO}_{2}$. To collect $\mathrm{HCC}$ stem cells, Hep3B cells were routinely digested and resuspended in staining buffer (BioLegend, Inc.) at $1 \times 10^{7}$ cells $/ \mathrm{ml}$, followed by incubation with phycoerythrin-CD133 (cat. no. 130-080-801; 1:11; Miltenyi Biotec $\mathrm{GmbH}$ ) and fluorescein isothiocyanate-CD44 (cat. no.11-0441-82; 1:1,000; eBioscience; Thermo Fisher Scientific, Inc.) antibodies at $4^{\circ} \mathrm{C}$ for $30 \mathrm{~min}$. The stained tumor cells were collected by a flow cytometer (BD Immunocytometry Systems) and cultured in DMEM/F12 containing 1X B27 (Invitrogen; Thermo Fisher Scientific, Inc.), $20 \mathrm{ng} / \mathrm{ml}$ basic fibroblast growth factor (Miltenyi Biotec $\mathrm{GmbH}$ ) and $20 \mathrm{ng} / \mathrm{ml}$ epidermal growth factor (Provitro Biosciences LLC) at $37^{\circ} \mathrm{C}$ and $5 \% \mathrm{CO}_{2}$.

HCC stem cell identification. After the collected cells had been cultured for $48 \mathrm{~h}$, HCC stem cell markers [sex-determining region Y-box2 (SOX2) and the octamer-binding transcription factor 4 (Oct4)] were detected by immunofluorescence. Briefly, cell-laden coverslips were soaked in $4 \%$ paraformaldehyde at $4^{\circ} \mathrm{C}$ for $30 \mathrm{~min}$. After the cells were permeabilized with $0.5 \%$ Triton X-100 and blocked in 5\% BSA (Sigma-Aldrich; Merck $\mathrm{KGaA}$ ) for $1 \mathrm{~h}$, they were incubated with antibodies against SOX2 (1:200, ab137385; Abcam) or Oct4 (1:200, ab18976; Abcam) overnight at $4^{\circ} \mathrm{C}$. On the following day, the cells were washed and incubated with Alexa Fluor 488-conjugated anti-rabbit IgG H\&L (1:500, ab150080; Abcam) for $1 \mathrm{~h}$ at room temperature. Finally, the nuclei were counterstained with DAPI, and the fluorescence signal was captured under a fluorescence microscope (XF-73; Olympus Corporation) at a magnification of $\mathrm{x} 200$.

Sphere formation assay. HCC stem cells $\left(1 \times 10^{3}\right.$ cells $\left./ \mathrm{ml}\right)$ were seeded in a 24-well culture plate containing a poly-lysine-coated coverslip and cultured for 7-10 days in DMEM/F12 medium containing 1 X B27, $20 \mathrm{ng} / \mathrm{ml}$ basic fibroblast growth factor, and $20 \mathrm{ng} / \mathrm{ml}$ epidermal growth factor with low-dose $\left(1 \times 10^{-7} \mathrm{M}\right)$, high-dose $\left(1 \times 10^{-5} \mathrm{M}\right)$, or no dexamethasone (Dex) (D4902; Sigma-Aldrich; Merck KGaA). Suspended cloned spheres with diameters $>50 \mu \mathrm{m}$ were counted under an inverted microscope (cell Sens Entry 1.16; Olympus Corporation) at magnifications of $\mathrm{x} 40$ and $\mathrm{x} 400$.

Cytotoxicity assay. To assess the side effects of various concentrations of Dex, mouse-derived bone marrow mesenchymal stem cells (BMSCs; Central Laboratory of The Fifth Central Hospital of Tianjin) were used. BMSCs were incubated in DMEM with $10 \% \mathrm{FBS}, 100 \mathrm{U} / \mathrm{ml}$ penicillin and $100 \mu \mathrm{g} / \mathrm{ml}$ streptomycin with low-dose $\left(1 \times 10^{-7} \mathrm{M}\right)$, high-dose $\left(1 \times 10^{-5} \mathrm{M}\right)$, or no Dex for $72 \mathrm{~h}$. Then, cell morphology was observed and lactate dehydrogenase ( $\mathrm{LDH})$ content in the culture supernatant was measured by an LDH Activity Assay Kit (Yuanmu Biotechnology Co., Ltd.), according to the manufacturer's instructions.

Western blotting. Total protein was extracted from cells by incubation in RIPA buffer (Beijing Solarbio Science \& Technology Co., Ltd.) supplemented with $1 \mathrm{mM}$ phenylmethanesulfonyl fluoride and $20 \mathrm{mMN}$-ethylmaleimide, as previously reported (19). Then, $100 \mu \mathrm{g}$ proteins were separated by $10 \%$ SDS-PAGE and then transferred onto a PVDF membrane (EMD Millipore, Inc.). Then, the membrane was blocked in 5\% BSA (Sigma-Aldrich; Merck KGaA) at room temperature for $1 \mathrm{~h}$ and incubated with the specific antibodies against SOX2 (ab137385; Abcam; 1:1,000), Oct4 ab18976; 1:1,000), SUMO1(ab11672; Abcam; 1:1,000), HIF-1a (ab216842; Abcam; 1:500), vimentin (5741; Cell Signaling Technology, Inc.; 1:1,000), E-cadherin (610404; BD Biosciences; $1: 500)$ and $\beta$-actin as an internal control (ab8227; Abcam; 1:1,000). The gray value of the bands was quantified by ImageJ image analysis software, version 1.48 (National Institutes of Health)

Wound healing assay. HCC stem cells were seeded into a 6-well plate at of $0.25 \times 10^{6}$ cells per well and cultured in DMEM/F12 at $37^{\circ} \mathrm{C}$ with $5 \% \mathrm{CO}_{2}$, as previously reported (20). When the confluence of the cell monolayer cells had reached $\sim 95 \%$, a scratch $\sim 1 \mathrm{~mm}$ wide was created using a $200-\mu 1$ pipette tip. Then, the cells were treated with or without $1 \times 10^{-7} \mathrm{M}$ Dex. Images were captured at 0 and $24 \mathrm{~h}$, an image was captured under an inverted microscope (cellSens Entry 1.16; Olympus Corporation) at a magnification of x200 and the distance between the edges of the scratch was measured by Image-Pro Plus 6.0 software (Media Cybernetics, Inc.).

Invasion assay. Cell invasion was assessed using a 24-well Transwell culture chamber with a filter pore size of $8 \mu \mathrm{m}$. 
A

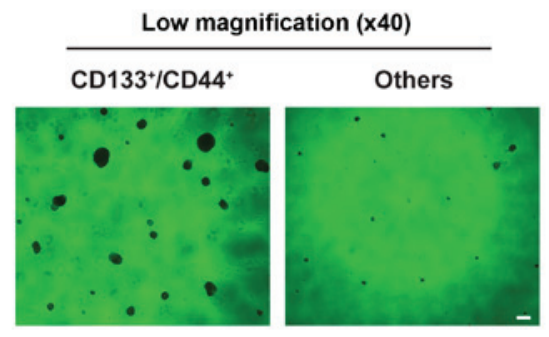

B
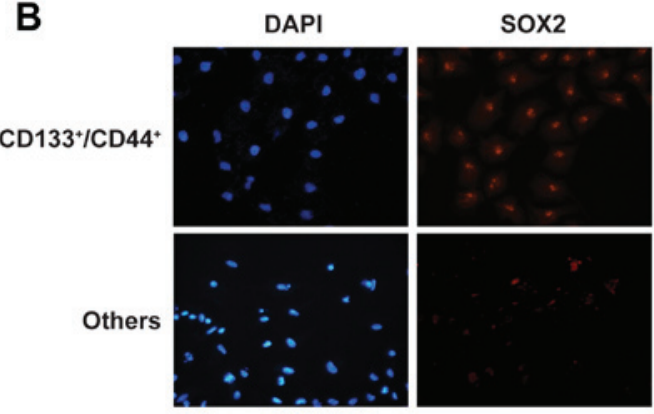

C

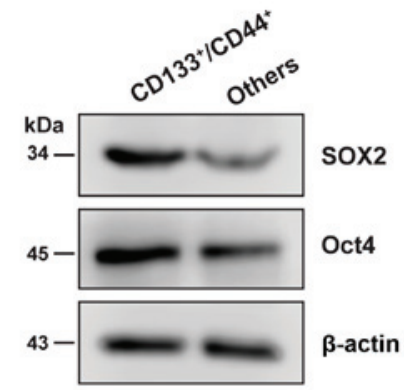

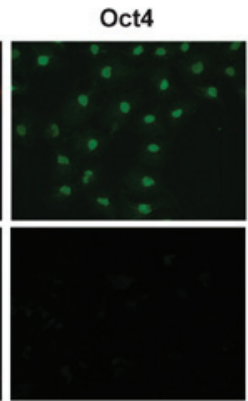
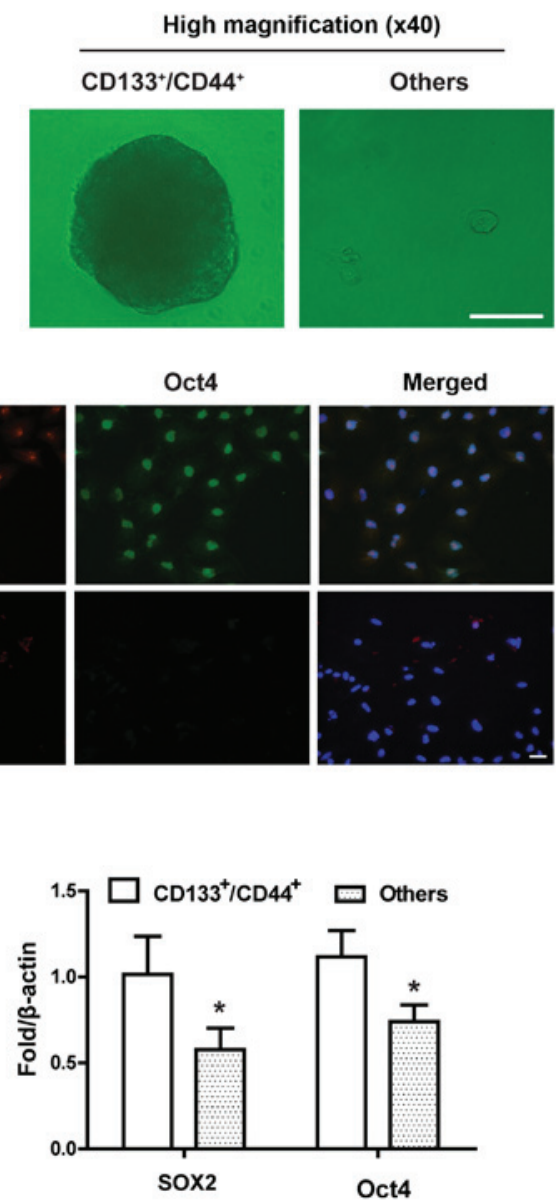

Figure 1. Successful isolation and identification of HCC stem cells. (A) CD133 $/$ CD $44^{+}$cells were capable of forming a large number of suspended cloned spheres. Conversely, other cells did not form cloned spheres (scale bar, $50 \mu \mathrm{m}$ ). Expression of SOX2 and Oct4 was examined by (B) immunofluorescence (scale bar, $50 \mu \mathrm{m})$ and $(\mathrm{C})$ western blotting. Data are shown as means $\pm \mathrm{SD}(\mathrm{n}=3) .{ }^{*} \mathrm{P}<0.05$ compared with the $\mathrm{CD} 133^{+} / \mathrm{CD} 44^{+}$group $(\mathrm{Student}$ 's t-test). $\mathrm{HCC}$, hepatocellular carcinoma; SOX2, sex-determining region Y-box2; Oct4, octamer-binding transcription factor 4.

Briefly, HCC stem cells $\left(1 \times 10^{4}\right.$ in $100 \mu 1$ medium with or without $1 \times 10^{-7} \mathrm{M}$ Dex) were seeded into the upper chamber precoated by Matrigel (1:3; BD Biosciences) at $37^{\circ} \mathrm{C}$ overnight, and DMEM containing $10 \%$ FBS was placed in the lower chamber. After incubation at $37^{\circ} \mathrm{C}$ for $48 \mathrm{~h}$, the cells invading to the lower surface of the membrane were stained with $0.2 \%$ crystal violet solution at room temperature for $10 \mathrm{~min}$. Then, the number of migrated cells was counted under an inverted microscope (cellSens Entry 1.16) at a magnification of x200.

Angiogenesis assay. The bottom of a 96-well plate was precoated with a 2-mm layer of semi-solid Matrigel (1:3; BD Biosciences) at $37^{\circ} \mathrm{C}$ overnight. Then, HCC stem cells $\left(0.25 \times 10^{6} /\right.$ well $)$ were seeded on the surface of the gel in $0.1 \mathrm{ml}$ medium with or without $1 \times 10^{-7} \mathrm{M}$ Dex. After incubation at $37^{\circ} \mathrm{C}$ for $96 \mathrm{~h}$, formation of blood vessels was observed under an inverted microscope (cellSens Entry 1.16) at a magnification of $\mathrm{x} 200$.

Apoptosis assay. Hep3B cells with stable herpes simplex virus thymidine kinase (HSVtk) gene transduction were provided by the Central Laboratory, The Fifth Central Hospital of Tianjin (Tianjin, China). The cells were seeded in 24-well plates with DMEM containing $1 \mathrm{mg} / \mathrm{ml}$ ganciclovir (GCV; cat. no. Y0001129; Sigma-Aldrich; Merck KGaA). After 24 h, the cells were harvested and apoptosis was analyzed by flow cytometry using an Annexin V-FITC/PI Apoptosis Detection kit (Invitrogen; Thermo Fisher Scientific, Inc.) according to the manufacturer's instructions. Briefly, the cells were washed twice with cold PBS and then resuspended in binding buffer. Subsequently, $100 \mu 1$ of the solution was supplemented by $5 \mu \mathrm{l}$ FITC Annexin V and $5 \mu \mathrm{l}$ PI. The cells were incubated for $15 \mathrm{~min}$ at $25^{\circ} \mathrm{C}$ in the dark. The experimental data were analyzed by flow cytometry within $1 \mathrm{~h}$.

Immunofluorescence. HCC stem cells were cultured on glass coverslips with or without $1 \times 10^{-7} \mathrm{M}$ Dex at $37^{\circ} \mathrm{C}$ for $48 \mathrm{~h}$. The expression of target proteins was detected by immunofluorescence with anti-SUMO1 (1:300, ab11672; Abcam), anti-HIF-1 $\alpha$ (1:100, ab216842; Abcam), or anti-Oct4 (1:100, ab18976; Abcam) antibodies.

Gene transduction. The transfer vector pWPXLD-GFP-HA-SUMO1 or pWPXLD-GFP or overexpressing vector for SUMO1/sentrin-specific peptidase 1 (pWPXLD-His-SENP1) or pWPXLD-His (Biogot Technology, Co., Ltd.), the packaging plasmid psPAX2 (Addgene, Inc.), and the envelope plasmid pMD2.G (Addgene, Inc.) were transfected 
A

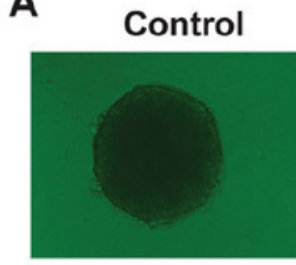

B

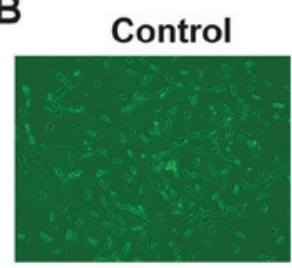

Dex (low)

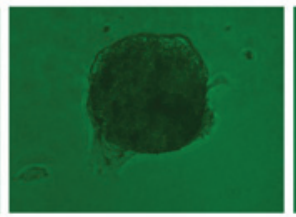

Dex (low)

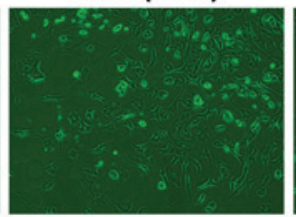

Dex (high)

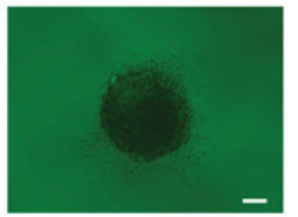

Dex (high)

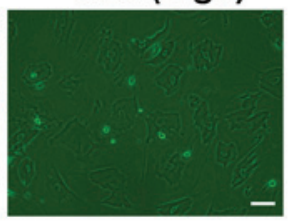

C

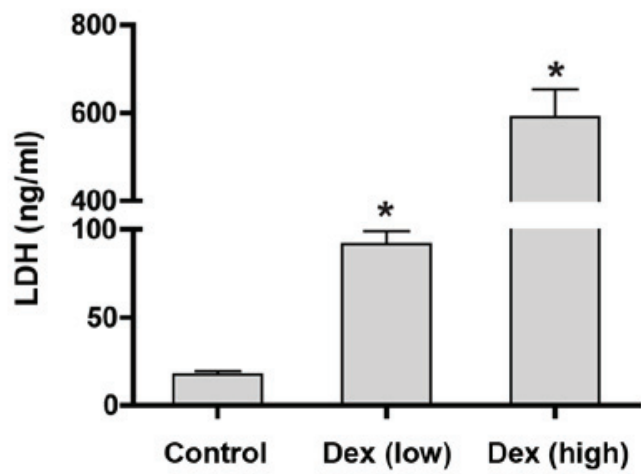

Figure 2. High-dose Dex damages mesenchymal stem cells and produces strong side effects. (A) HCC stem cells were treated with various concentrations of Dex and their morphological changes were observed under a microscope (scale bar, $20 \mu \mathrm{m}$ ). (B) The effects of various doses of Dex on BMSC cytotoxicity were assessed by morphological changes (scale bar, $50 \mu \mathrm{m}$ ) and (C) LDH assay. Data are shown as means $\pm \mathrm{SD}(\mathrm{n}=3)$. " $\mathrm{P}<0.05$ compared with the control group (Student's t-test). HCC, hepatocellular carcinoma; Dex, dexamethasone; BMSC, bone marrow stem cell; LDH, lactate dehydrogenase.

into 293T cells at the ratio of 4:3:1 for production of lentiviral particles. Lipofectamine $2000^{\mathrm{TM}}$ (Thermo Fisher Scientific, Inc.) was used as the transfection reagent, and the ratio of transfection reagent to plasmid was 1:2.5. The supernatant was filtered through a $0.45-\mu \mathrm{m}$ filter and was concentrated by passing through an ultrafiltration tube (EMD Millipore). The concentrated virus was used to infect Hep3B cells with $20-30 \%$ confluence $\left(5-10^{5}\right.$ cells) in a $60-\mathrm{mm}$ dish with $8 \mathrm{mg} / \mathrm{ml}$ polybrene. After $48 \mathrm{~h}$, western blotting was used to verify the gene transduction efficiency. The extent of cellular phenotypic changes was detected by the methods mentioned above.

Xenograft tumor assay. All animal experiments in the present study met the ethical requirements of the Animal Ethics Committee of Tianjin Fifth Central Hospital (Tianjin, China). The mice were kept at the Experimental Animal Center of The Fifth Central Hospital of Tianjin that conforms to international certification standards. A total of $50 \mathrm{BALB} / \mathrm{c}$ female athymic mice (aged 6 weeks and weighing 14-16 g) were injected subcutaneously with $5 \times 10^{6} \mathrm{HSVtk} / \mathrm{Hep} 3 \mathrm{~B}$ stem cells. When the subcutaneous tumor volume approached $100 \mathrm{~mm}^{3}$, the mice were randomly assigned to five experimental groups $(n=10)$ that received vehicle, SUMO1 plasmid $(10 \mathrm{mg} / \mathrm{kg})$, Dex (10 mg/kg), or combined SUMOl plasmid and Dex, while GCV (15 mg/kg) was injected intraperitoneally every other day up to 28 days. The longest and shortest diameters of the tumor were measured every 3 days using vernier calipers, and the tumor volume was calculated using the formula: $\mathrm{V}=\mathrm{L} \times \mathrm{W} 2 \times 0.5$ (L, length; W, width). On the 28th day, the mice were euthanized with $\mathrm{CO}_{2}$ gas in sealed chambers at a flow rate of $25 \%$ volume $/ \mathrm{min}$. The tumors were resected and apoptosis was detected using an in situ cell death kit (Roche Diagnostics), according to the manufacturer's protocol.

Statistical analysis. All experiments were repeated at least three times. The data were analyzed using GraphPad Prism 6 (GraphPad Software, Inc.). Measurement data are presented as means \pm SD. Comparisons between two groups were analyzed using Student's t-test. Differences among multiple groups was analyzed by one-way ANOVA followed by Tukey's post hoc test. $\mathrm{P}<0.05$ was considered to indicate statistically significant differences.

\section{Results}

Successful isolation and identification of HCC stem cells. $\mathrm{CD} 133^{+} / \mathrm{CD} 44^{+}$cells sorted by flow cytometry were capable of forming a large number of suspended cloned spheres. Conversely, other cells (including CD133\%/CD44-

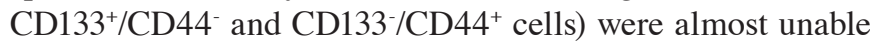
to form cloned spheres (Fig. 1A). Immunofluorescence and western blot analysis demonstrated that the $\mathrm{CD} 133^{+} / \mathrm{CD} 44^{+}$ cells expressed both SOX2 and Oct4, whereas the other cells hardly expressed the two stem cell markers (Fig. 1B and C). These results confirmed that the collected $\mathrm{CD} 133^{+} / \mathrm{CD} 44^{+}$ cells were HCC stem cells.

High-dose Dex damages mesenchymal stem cells and produces strong side effects. High doses of Dex are often used with caution due to the severe clinical side effects (21). According to the shape of the HCC stem cell cloned sphere, although low doses of Dex increased the adhesion of the cloned spheres to the bottom of the culture dish, they did not appear to significantly induce differentiation or aging of these cells. However, high doses of Dex significantly increased adhesion and aging of HCC stem cells (Fig. 2A). Next, the toxicity of various doses of Dex against BMSCs was examined. The results demonstrated that low-dose Dex changed the morphology of BMSCs, mainly from spindled to polygonal, whereas high-dose Dex caused significant aging (Fig. 2B). The results of cytotoxicity assays demonstrated that low doses of Dex slightly increased the LDH content in the culture supernatant of BMSCs, whereas high doses of Dex significantly increased the LDH levels (Fig. 2C).

Low doses of Dex suppress the malignant behavior of HCC stem cells and increase chemosensitivity. SOX 2 and Oct 4 are involved in stemness maintenance of HCC stem cells (22). The results of the present study demonstrated that Dex reduced the protein levels of SOX2 and Oct4, suggesting that 
A
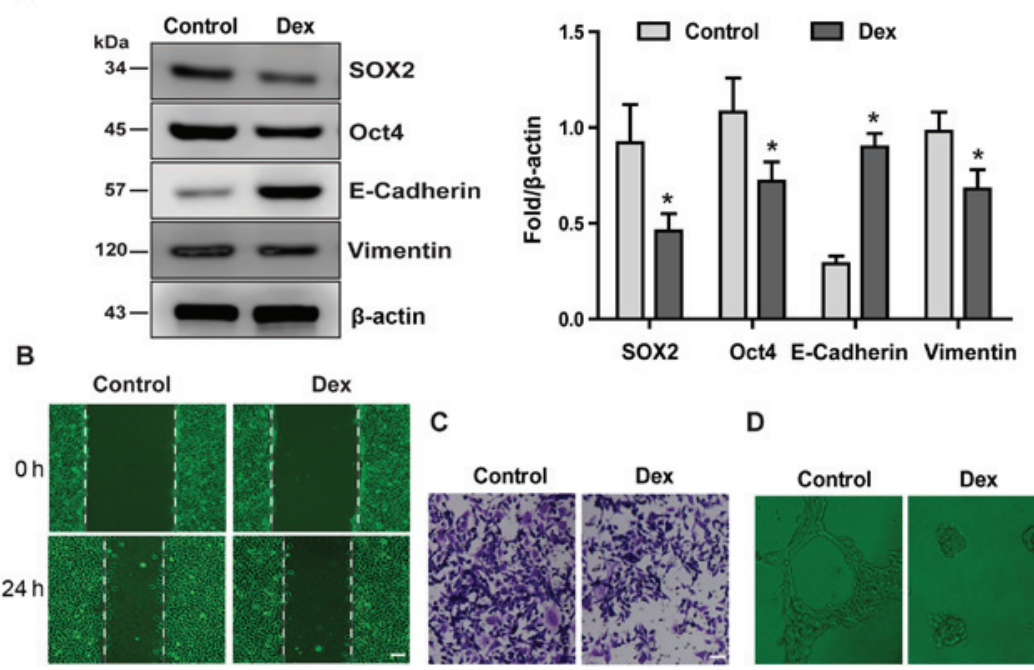

C

D

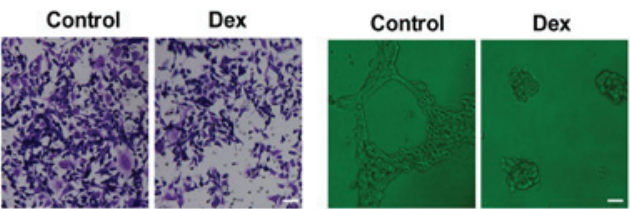

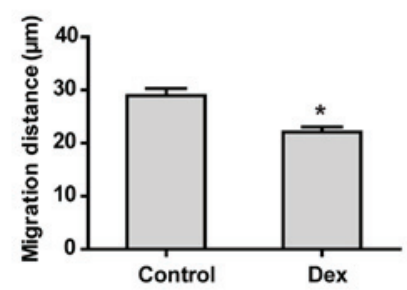

G

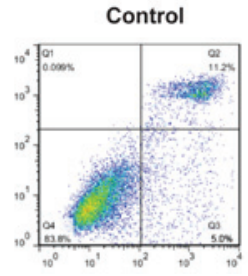

$\mathbf{F}$

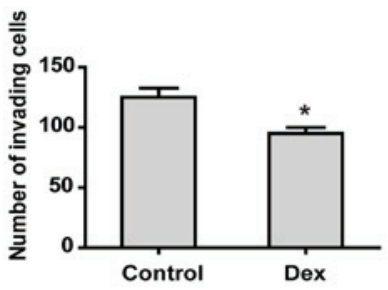

H

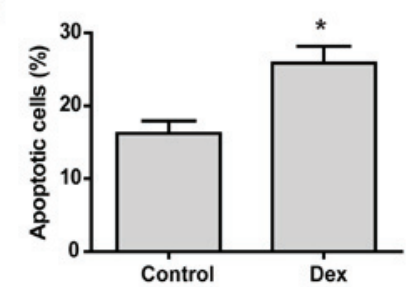

Figure 3. Low doses of Dex suppressed the malignant behavior of HCC stem cells and increased chemosensitivity. (A) The expression of stemness markers and major epithelial-to-mesenchymal transition-associated proteins was examined by western blotting. (B and E) The effects of low-dose Dex on the malignant behavior of HCC stem cells were analyzed by wound healing (scale bar, $50 \mu \mathrm{m}$ ), (C and F) invasion (scale bar, $50 \mu \mathrm{m}$ ), (D) angiogenesis (scale bar, $20 \mu \mathrm{m})$ and $(\mathrm{G}$ and $\mathrm{H})$ apoptosis assays. Data are shown as means $\pm \mathrm{SD}(\mathrm{n}=3)$. " $\mathrm{P}<0.05$ compared with the control group (Student's t-test). HCC, hepatocellular carcinoma; Dex, dexamethasone.

low-dose Dex reduced the stemness maintenance potential of HCC stem cells (Fig. 3A). Elevated vimentin protein levels and decreased E-cadherin protein levels are important markers of epithelial-to-mesenchymal transition (EMT) (23). Our results demonstrated that Dex reduced vimentin levels, while it increased E-cadherin levels, suggesting that low-dose Dex inhibited EMT of HCC stem cells (Fig. 3A). Next, the effect of low-dose Dex on the malignant behavior of HCC stem cells was examined. Low-dose Dex suppressed the malignant behavior of HCC stem cells, including self-repair (Fig. 3B and E), invasion (Fig. 3C and F), neovascularization (Fig. 3D) ability, and increased the sensitivity of HCC stem cells to HSVtk/GCV treatment (Fig. 3G and H).

Low doses of Dex reduce SUMOylation of target proteins and inhibit nuclear translocation of HIF-1 $\alpha$ and Oct4. SUMO modification usually acts by stabilizing the target protein structure and inhibiting degradation and the shift from the cytoplasm to the nucleus by antagonizing ubiquitination modification (24-26). In the present study, how Dex affects the SUMOylation of target proteins was investigated. The results demonstrated that low doses of Dex significantly reduced the covalent modification of target proteins (Fig. 4A). HIF-1 $\alpha$ and Oct4 are two confirmed SUMO1 target proteins $(27,28)$. Therefore, the effects of Dex on HIF-1 $\alpha$ and Oct 4 protein expression were examined. The results demonstrated that low-dose Dex significantly reduced the expression of HIF-1 $\alpha$ and Oct4 proteins (Fig. 4A), while it inhibited their translocation from the cytoplasm to the nucleus (Fig. 4B and C).

Overexpression of SUMO1 slightly affects the malignant phenotype of HCC stem cells. The effects of SUMO1 overexpression on the malignant phenotype of HCC stem cells were next examined. The results demonstrated that overexpression of SUMO1 only slightly affected the malignant phenotype of HCC stem cells, including stemness maintenance and EMT (Fig. 5A and B), wound healing (Fig. 5C and G), migration (Fig. 5D and $\mathrm{H}$ ) and angiogenesis (Fig. 5E). In addition, overexpression of SUMO1 did not significantly affect the sensitivity of HCC stem cells to HSVtk/GCV (Fig. 5F and I).

Overexpression of SENPI partially antagonizes the effect of Dex on the malignant phenotype of HCC stem cells. 

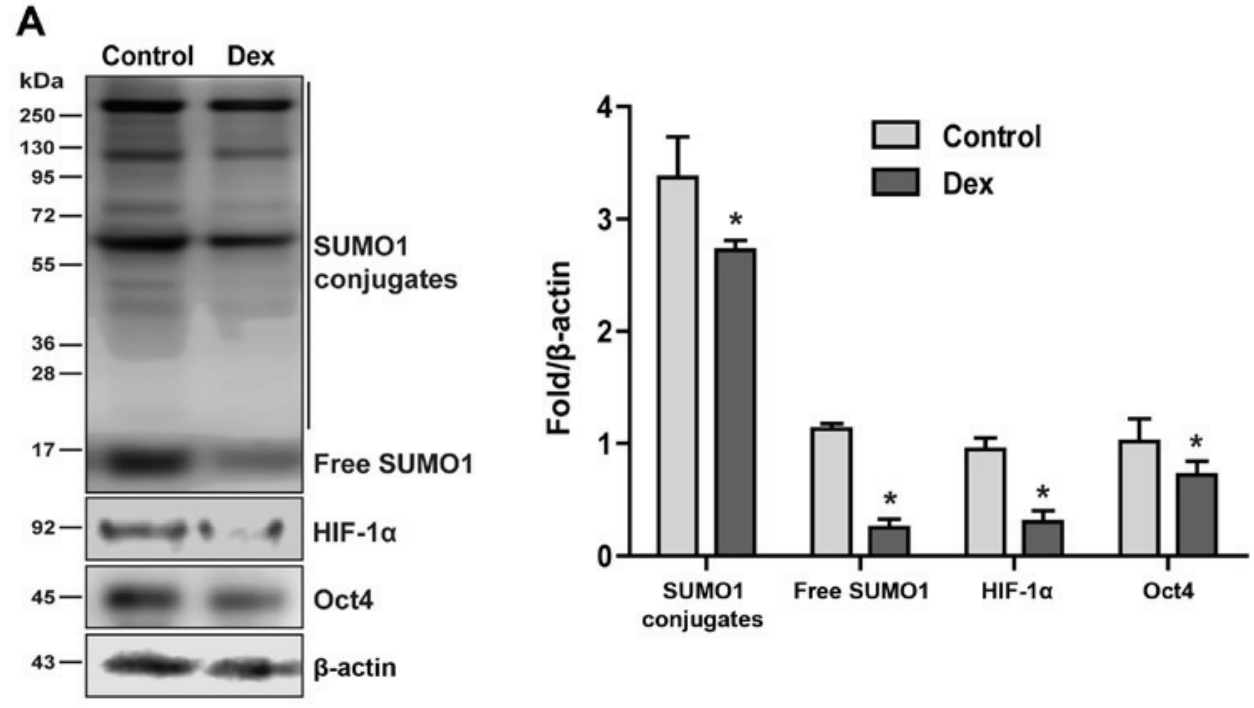

B
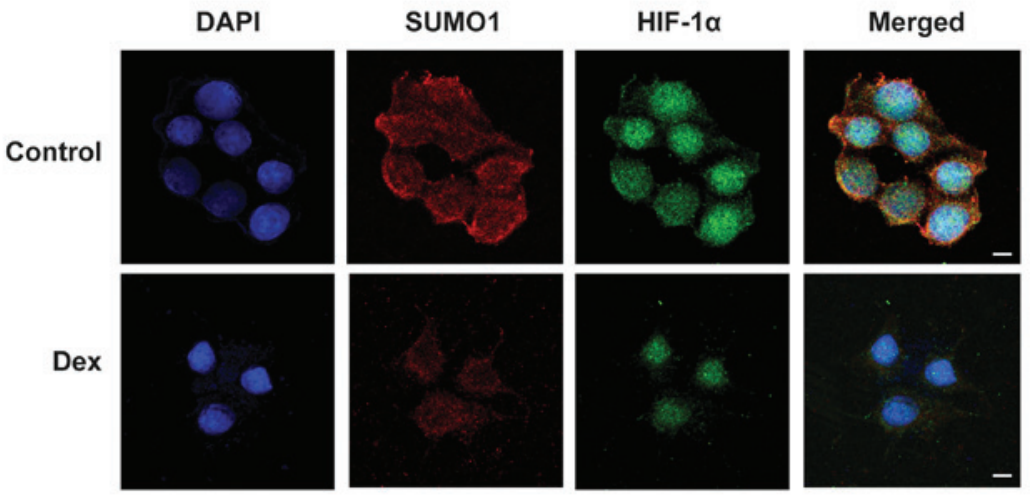

C

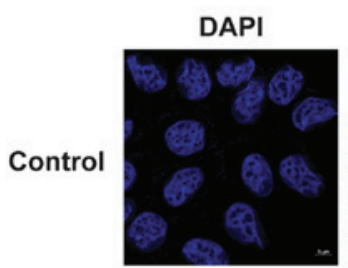

SUM01
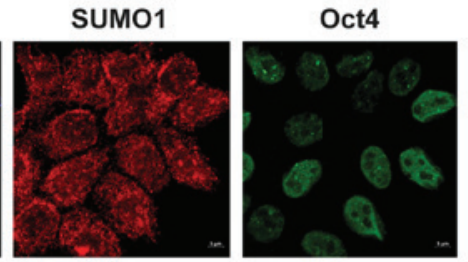

Merged
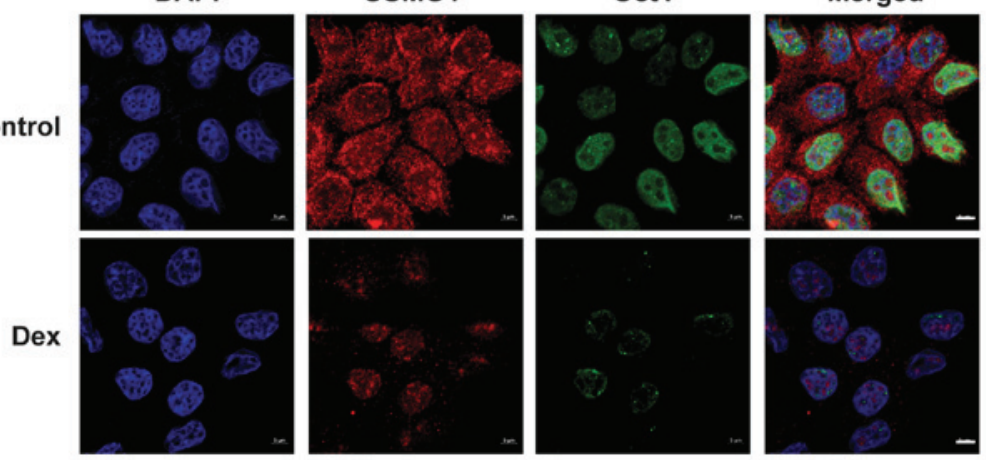

Figure 4. Low doses of Dex reduced SUMOylation of target proteins and inhibited nuclear translocation of HIF-1 $\alpha$ and Oct4. (A) The effects of Dex on protein expression of SUMO1, HIF-1 $\alpha$ and Oct4 were examined by western blotting. (B) The effects of Dex on the expression and cytoplasmic shift of SUMO1 and HIF-1 $\alpha$ were analyzed by immunofluorescence (scale bar, $20 \mu \mathrm{m}$ ). (C) The effects of Dex on expression and cytoplasmic shift of SUMO1 and Oct4 were analyzed by immunofluorescence (scale bar, $20 \mu \mathrm{m}$ ). Data are shown as means $\pm \mathrm{SD}(\mathrm{n}=3)$. " $\mathrm{P}<0.05$ compared with the control group (Student's t-test). Dex, dexamethasone; SUMO, small ubiquitin-like modifier; HIF-1 $\alpha$, hypoxia inducible factor-1 $\alpha$; Oct 4 , octamer-binding transcription factor 4.

Next, the effects of SENP1 overexpression on malignant phenotypic changes of HCC stem cells induced by Dex were examined. Compared with normal HCC stem cells, HCC stem cells overexpressing SENP1 exhibited a stronger stemness maintenance ability and partially inhibited EMT (Fig. 6A and B), enhanced wound healing (Fig. 6C and G), increased migration (Fig. 6D and $\mathrm{H}$ ) and angiogenesis (Fig. 6E) under Dex treatment. More importantly, overexpression of SENP1 decreased the sensitivity of HCC stem cells to HSVtk/GCV when combined with Dex treatment (Fig. 6F and I).
Overexpression of SUMOI decreases the sensitivity of HCC stem cells to HSVtk/GCV when combined with Dex in vivo. Finally, the effects of SUMO1 overexpression combined with Dex on the sensitivity of HCC stem cells to HSVtk/GCV were observed in a tumor-bearing mouse model. Although administration of HSVtk/GCV or Dex alone inhibited the growth of subcutaneous HCC tumors and caused tumor cell apoptosis, the tumor continued to grow until the tumor-bearing mice were sacrificed (Fig. 7A-D). However, upon combined application of SUMO1 and Dex, the sensitivity of HCC stem cells to HSVtk/GCV was reduced, which was characterized 


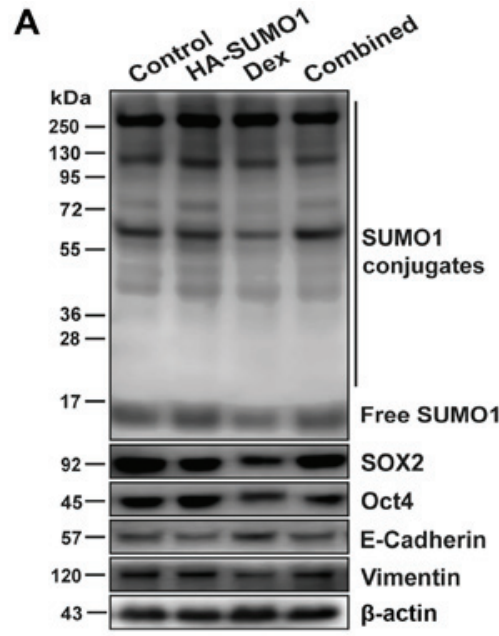

B
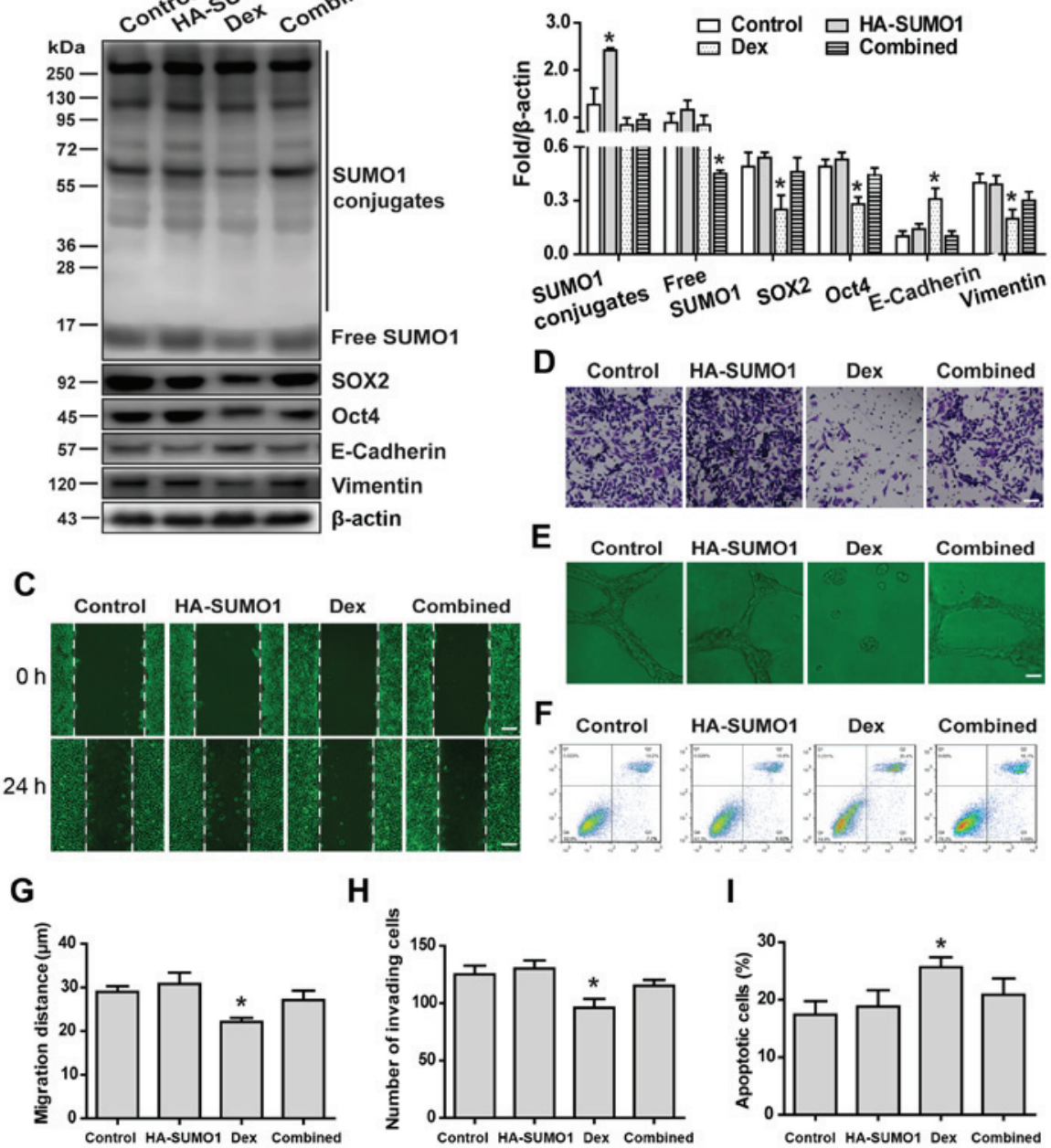

E

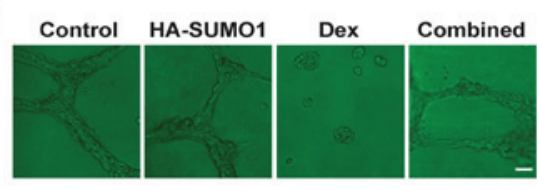

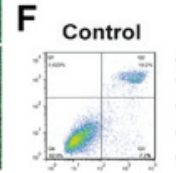

H

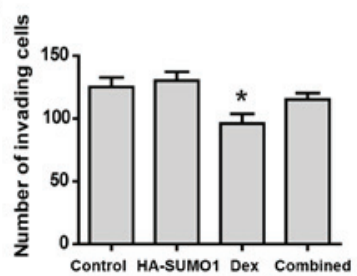

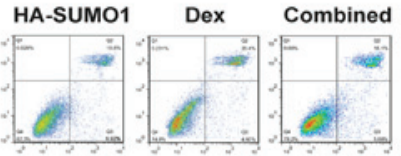

I

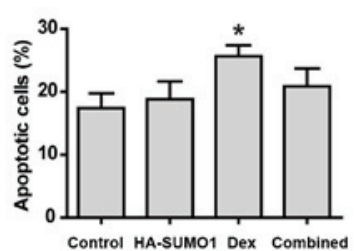

Figure 5. Overexpression of SUMO1 slightly affects the malignant phenotype of HCC stem cells. (A and B) The effects of SUMO1 overexpression and Dex or their combination on stemness maintenance and EMT-related protein expression of HCC stem cells were examined by western blotting. The malignant phenotypes caused by SUMO1 overexpression and Dex or their combination were examined by (C and G) wound healing (scale bar, $50 \mu \mathrm{m}),(\mathrm{D}$ and $\mathrm{H})$ invasion (scale bar, $50 \mu \mathrm{m}$ ), (E) angiogenesis (scale bar, $20 \mu \mathrm{m}$ ), and (F and I) apoptosis assays. Data are shown as means $\pm \mathrm{SD}(\mathrm{n}=3)$. " $\mathrm{P}<0.05$ compared with the control group (Student's t-test). SUMO, small ubiquitin-like modifier; HCC, hepatocellular carcinoma; EMT, epithelial-to-mesenchymal transition; Dex, dexamethasone.

by accelerated tumor growth and lower rate of tumor cell apoptosis (Fig. 7A-D).

\section{Discussion}

HCC is the main histological subtype of liver cancer, accounting for $90 \%$ of primary liver cancers (1). In recent years, the incidence rate of HCC in China has gradually increased, which has been attracting increasing attention (29). Due to the structural features of the rich liver blood transport and the powerful compensatory function, liver cancer grows rapidly and is prone to metastasis. Therefore, the clinical diagnosis mostly occurs in the mid- and late stages of the disease, when the opportunity for surgical resection has been missed and the prognosis is poor (30). Surgical resection and liver transplantation are the main methods for treating liver cancer, but intrahepatic metastasis and postoperative recurrence adversely affect the prognosis $(31,32)$. Liver transplantation is often abandoned due to the shortage of liver donors. Therefore, it is crucial to explore new methods for treating liver cancer based on traditional surgery, chemotherapy, radiotherapy, as well as other treatment strategies.
HSVtk/GCV systems have been highly anticipated for the treatment of multiple solid tumors, including breast cancer, gastric cancer, brain tumors and HCC (33-35). Theoretically, HSVtk catalyzes GCV phosphorylation, and then phosphorylated GCV binds to DNA polymerase, interrupting the DNA replication process, hindering cell division and, therefore killing tumor cells. However, the discovery of cancer stem cells has uncovered a weakness of the HSVtk/GCV system, as it cannot kill cells in the $\mathrm{G}_{0}$ phase. Improving the therapeutic sensitivity of HSVtk/GCV in cancer stem cells has come to represent a new challenge.

Dex has been widely used in clinical practice for several years. In recent years, it has been reported that this drug affects glucose metabolism in HCC cells and inhibits tumor growth (36-38). However, whether Dex can be combined with other chemotherapeutic drugs to treat tumors has been a subject of debate among clinicians. Therefore, Dex was combined with HSVtk/GCV to assess its therapeutic effect on HCC stem cells in the present study.

The survival of tumor stem cells under hypoxic conditions is dependent on stable expression of the HIF-1 $\alpha$ protein, and their stemness maintenance is dependent on stable Oct4 
A

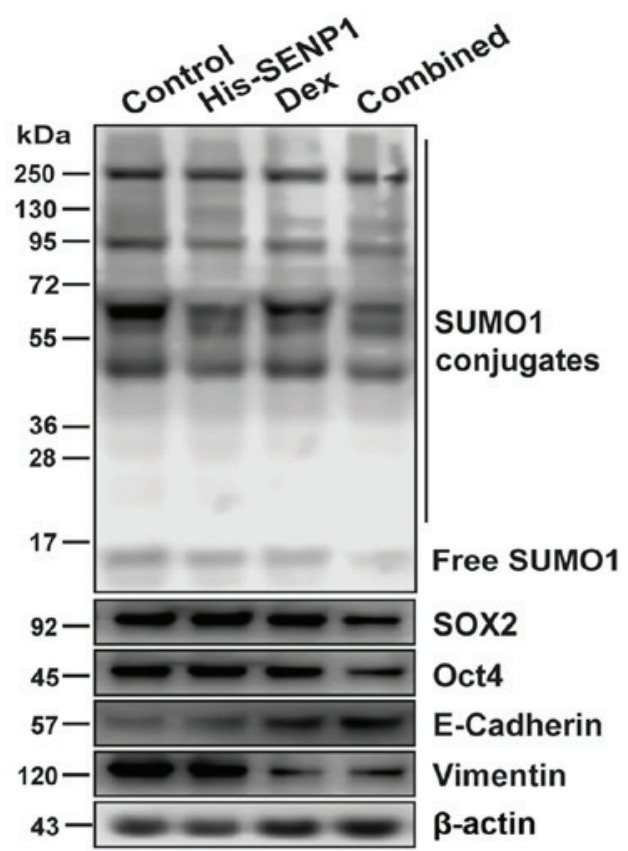

B

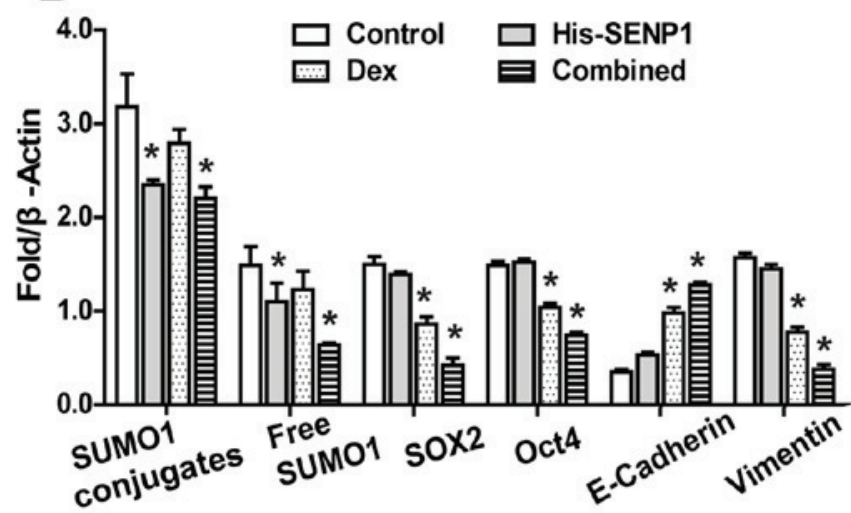

D

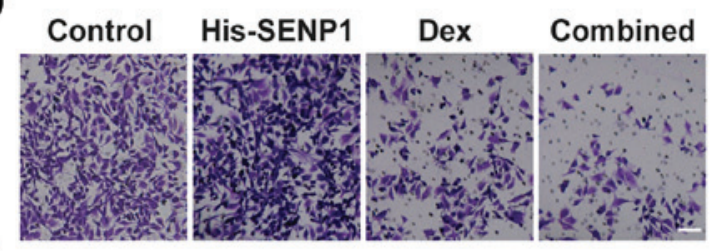

E

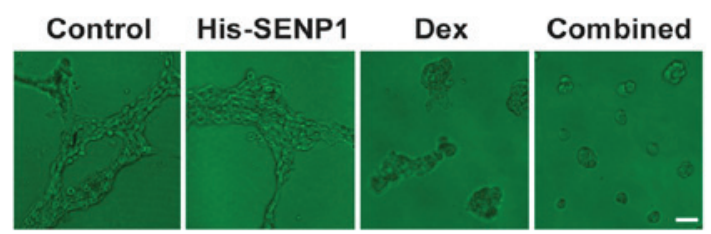

$\mathbf{F}$
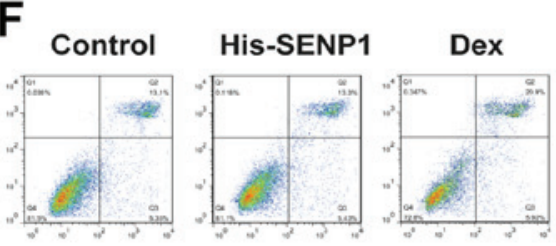

Combined

$24 \mathrm{~h}$
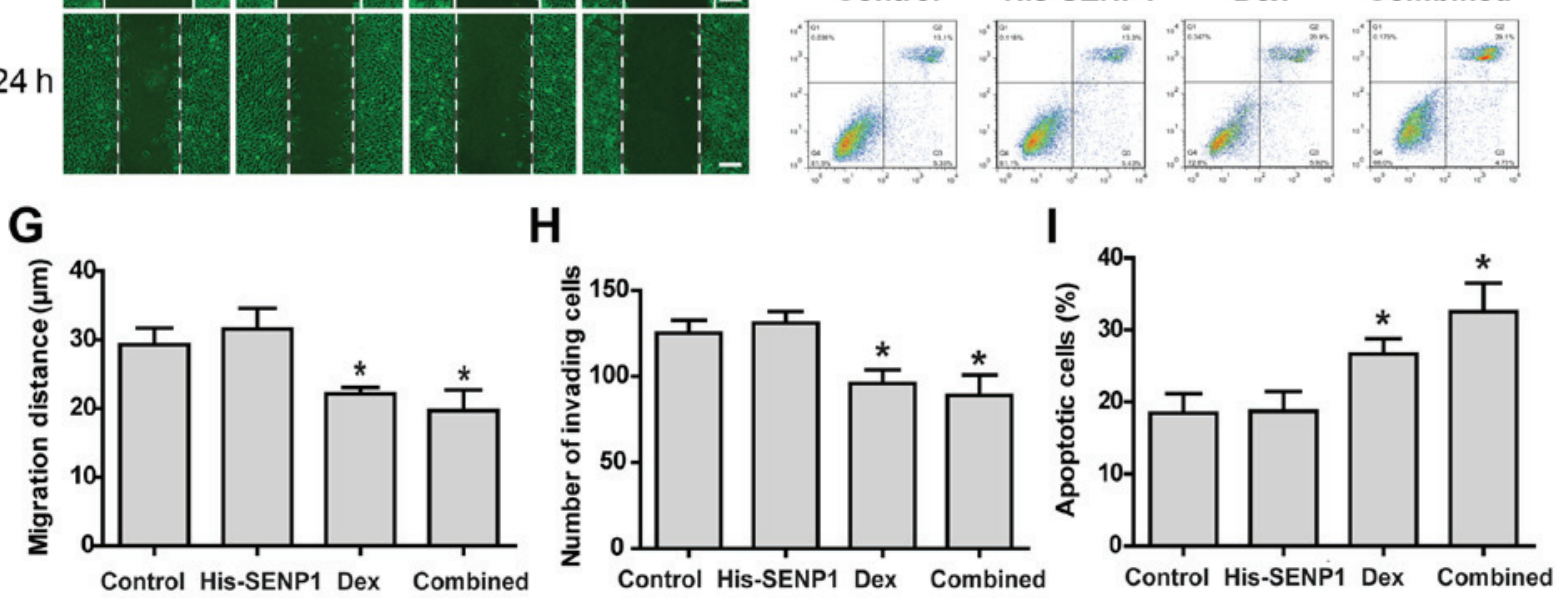

Figure 6. Overexpression of SENP1 partially antagonizes the effect of Dex on the malignant phenotype of HCC stem cells. (A and B) The effects of SENP1 overexpression and Dex or their combination on stemness maintenance and epithelial-to-mesenchymal transition-related protein expression of HCC stem cells were examined by western blotting. The malignant phenotypes caused by SENP1 overexpression and Dex or their combination were examined by (C and G) wound healing (scale bar, $50 \mu \mathrm{m}$ ), (D and H) invasion (scale bar, $50 \mu \mathrm{m}$ ), (E) angiogenesis (scale bar, $20 \mu \mathrm{m}$ ) and (F and I) apoptosis assays. Data are shown as means $\pm \mathrm{SD}(\mathrm{n}=3)$. ${ }^{*} \mathrm{P}<0.05$ compared with the control group (Student's t-test). SENP1, SUMO1/sentrin-specific peptidase 1; HCC, hepatocellular carcinoma; Dex, dexamethasone.

expression in the nucleus $(39,40)$. The stable presence of HIF-1 $\alpha$ and Oct4 in the nucleus is known to depend on a dynamic equilibrium state mediated by ubiquitin and SUMO modification (41). Typically, ubiquitin modification mediates degradation of target proteins, whereas SUMO modification antagonizes this process (42). However, whether Dex can change the stable forms of HIF-1 $\alpha$ and Oct4 proteins in cells by affecting this dynamic balance remains unknown.

In the present study, HCC stem cells and BMSCs were first treated with low- and high-dose Dex to assess the effects. Although high-dose Dex induced aging of HCC stem cells, it also induced severe aging of BMSCs, suggesting that high-dose Dex causes abnormalities in mesenchymal stem cells, leading to serious side effects. Therefore, subsequent experiments used low-dose Dex to treat HCC stem cells to avoid adverse reactions. Next, the effect of low-dose Dex on the malignant phenotype of HCC stem cells were observed. The results demonstrated that low-dose Dex inhibited the malignant phenotype of HCC stem cells, particularly by increasing their sensitivity to HSVtk/GCV. We then 
A

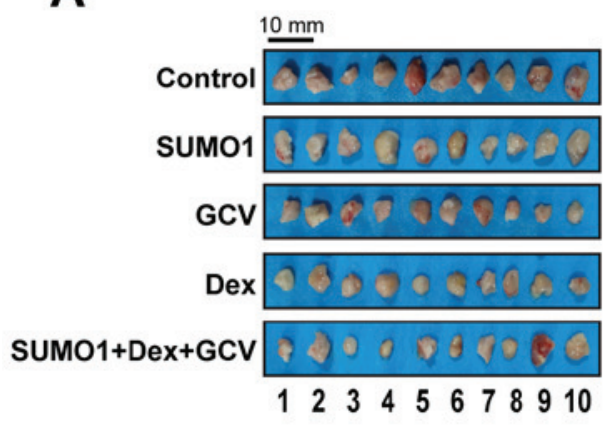

D
B

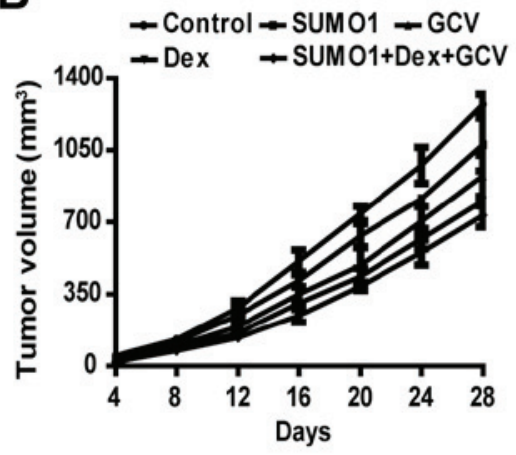

C

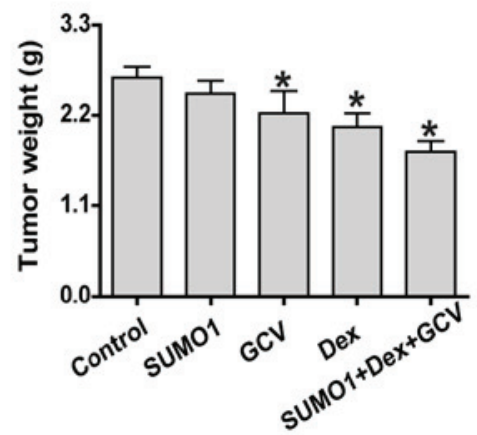

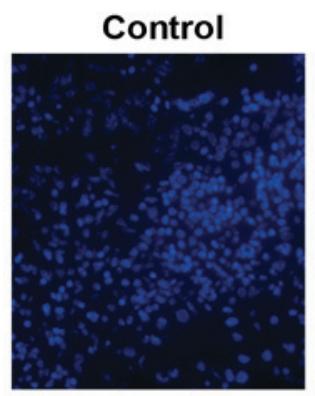
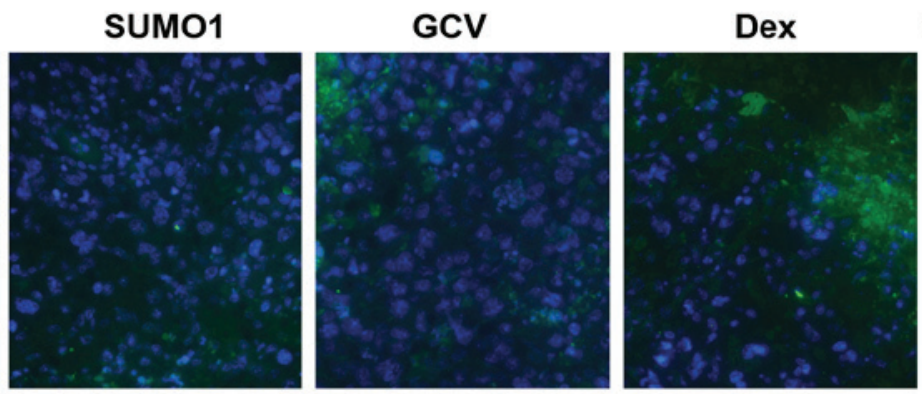

SUM01+Dex+GCV

Figure 7. Overexpression of SUMO1 decreases the sensitivity of HCC stem cells to HSVtk/GCV when combined with dexamethasone in vivo. (A) Subcutaneous tumors were dissected from nude mice and photographed. (B) Tumor volumes were measured every 3 days for 28 days. (C) Tumors were weighted immediately after dissection from nude mice. (D) Apoptosis in tumor xenograft sections was detected by TUNEL staining (scale bar, $20 \mu \mathrm{m}$ ). Data are shown as means \pm SD $(\mathrm{n}=3) .{ }^{*} \mathrm{P}<0.05$ compared with the control group (Student's t-test). SUMO, small ubiquitin-like modifier; HCC, hepatocellular carcinoma; HSVtk/GCV, herpes simplex virus thymidine kinase/ganciclovir drug system.

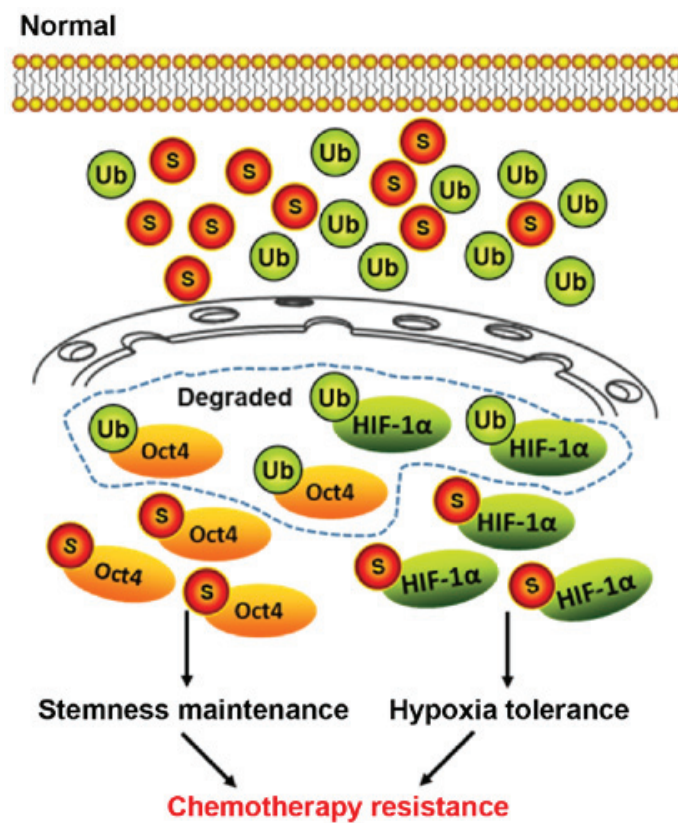

Dex

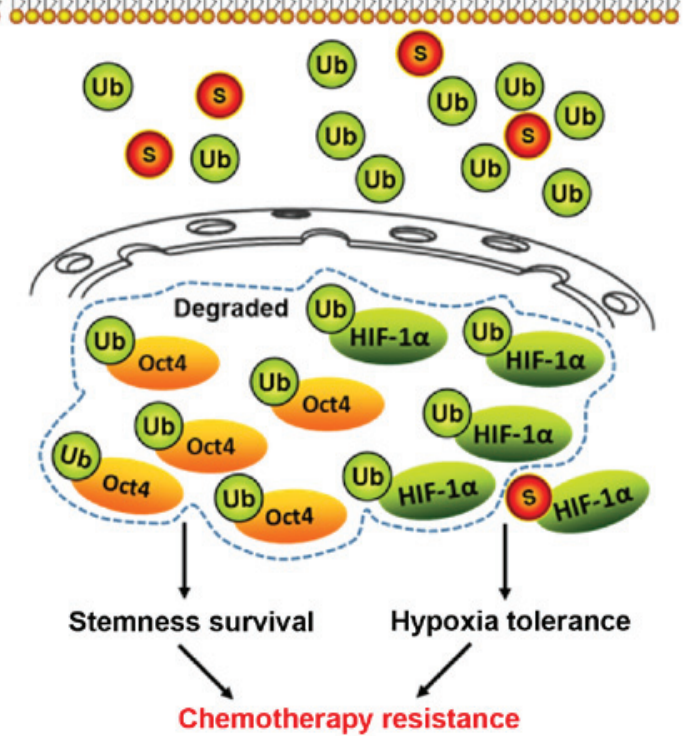

Figure 8. Schematic summary of the findings of the present study. Dex inhibited stemness maintenance and enhanced the chemosensitivity of hepatocellular carcinoma stem cells by inducing deSUMOylation of HIF-1 $\alpha$ and Oct4. SUMO, small ubiquitin-like modifier; Dex, dexamethasone; HIF-1 $\alpha$, hypoxia inducible factor-1 $\alpha$; Oct 4 , octamer-bindingtranscription factor 4.

examined the effect of Dex on the expression of HIF-1 $\alpha$ and Oct 4 proteins. The results revealed that low-dose Dex reduced the degree of SUMOylation of both HIF-1 $\alpha$ and Oct 4 , increased their degradation, and inhibited their translocation from the cytoplasm to the nucleus, thereby reducing their accumulation and stable presence in the nucleus and ultimately reducing hypoxia tolerance and stemness maintenance potential. 
To investigate the effect of low-dose Dex on the sensitivity of $\mathrm{HCC}$ stem cells to HSVtk/GCV, gene transduction was used to obtain HCC stem cells overexpressing SUMO1. First, it was observed that overexpression of SUMO1 only mildly affected the malignant phenotype of HCC stem cells, but increased their therapeutic sensitivity to HSVtk/GCV in vitro and in vivo. More importantly, overexpression of SUMO1 partially antagonized the effect of Dex on the malignant phenotype of HCC stem cells and further increased their sensitivity to HSVtk/GCV. Therefore, Dex inhibited stemness maintenance and enhanced chemosensitivity of HCC stem cells by inducing deSUMOylation of HIF-1 $\alpha$ and Oct4 (Fig. 8).

These results may enable a better understanding of the mechanism through which Dex enhances the therapeutic sensitivity of HCC stem cells to HSVtk/GCV from the perspective of protein ubiquitination and SUMO modification equilibrium. However, Dex increases the sensitivity to chemotherapy drugs, while partially restoring the malignant phenotype of HCC stem cells. In conclusion, the combined application of Dex and other chemotherapeutic drugs requires further extensive research in order to improve its strengths and limit or avoid adverse effects.

\section{Acknowledgements}

Not applicable.

\section{Funding}

The present study was supported by the National Natural Science Foundation of China (grant nos. 81901526 and 81900407), the Tianjin Natural Science Foundation of China (grant nos. 18JCQNJC12800, 19JCZDJC35200, 19JCQNJC12100 and 19JCQNJC11900), the Tianjin Special Project of New Generation Artificial Intelligence Technology (grant no. 18ZXZNSY00260) and the Binhai Health and Family Planning Commission Science and Technology Projects (grant nos. 2019BWKQ030 and 2019BWKQ029).

\section{Availability of data and materials}

The datasets used and/or analyzed during the present study are available from the corresponding author on reasonable request.

\section{Authors' contributions}

WHW and PZ designed the experiments. ZMJ, CYZ, XFM, RG and YJS performed the experiments and collected data. ZMJ, CYZ, XZL, XYB and XXX analyzed and interpreted the data. ZMJ, CYZ and XZL drafted the manuscript. ZMJ, WHW and PZ revised the paper critically for important intellectual content. WHW and PZ agree to be accountable for all aspects of the work in ensuring that questions related to the accuracy or integrity of any part of the work are appropriately investigated and resolved. All the authors have read and approved the final version of the manuscript for publication.

\section{Ethics approval}

The animal experimental protocols were reviewed and approved by the Ethics Committee of the Fifth Central Hospital of Tianjin.

\section{Patient consent for publication}

Not applicable.

\section{Competing interests}

All the authors declare that they have no competing interests.

\section{References}

1. Siegel RL, Miller KD and Jemal A: Cancer statistics, 2019. CA Cancer J Clin 69: 7-34, 2019.

2. El-Karaksy HM, Mogahed E, El-Sayed R, El-Raziky M, Sheba M, Besheer M, Elkiki H and Ghita H: Focal hepatic lesions in Egyptian infants and children: The pediatric hepatologist perspective. Minerva Pediatr 70: 35-45, 2018.

3. Hartke J, Johnson M and Ghabril M: The diagnosis and treatment of hepatocellular carcinoma. Semin Diagn Pathol 34: 153-159, 2017.

4. Li Y, Ruan DY, Jia CC, Zhao H, Wang GY, Yang Y and Jiang N: Surgical resection versus liver transplantation for hepatocellular carcinoma within the Hangzhou criteria: A preoperative nomogram-guided treatment strategy. Hepatobiliary Pancreat Dis Int 16: 480-486, 2017

5. Gnutzmann D, Kortes N, Sumkauskaite M, Schmitz A, Weiss KH and Radeleff B: Transvascular therapy of hepatocellular carcinoma (HCC), status and developments. Minim Invasive Ther Allied Technol 27: 69-80, 2018.

6. da Motta Girardi D, Correa TS, Crosara Teixeira M and Dos Santos Fernandes G: Hepatocellular carcinoma: Review of targeted and immune therapies. J Gastrointest Cancer 49: 227-236, 2018.

7. Lui WY, P'eng FK, Chang YF, Chang TJ, Tsai TF, Hsu ML, Su TS, Tsay SH, Wu CW, Liu TY, et al: Analysis of glucocorticoid receptors in human hepatocellular carcinoma and HepG2 cells. Hepatology 18: 1167-1174, 1993.

8. Ray K: Hepatocellular carcinoma: restoring gluconeogenesis: steroids could treat liver cancer. Nat Rev Gastroenterol Hepatol 10: 693, 2013.

9. Woods CP, Hazlehurst JM and Tomlinson JW: Glucocorticoids and non-alcoholic fatty liver disease. J Steroid Biochem Mol Biol 154: 94-103, 2015.

10. Lee DH, Cheul Oh S, Giles AJ, Jung J, Gilbert MR and Park DM: Cardiac glycosides suppress the maintenance of stemness and malignancy via inhibiting HIF-1 $\alpha$ in human glioma stem cells. Oncotarget 8: 40233-40245, 2017.

11. Xiang L, Gilkes DM, Chaturvedi P, Luo W, Hu H, Takano N, Liang H and Semenza GL: Ganetespib blocks HIF-1 activity and inhibits tumor growth, vascularization, stem cell maintenance, invasion, and metastasis in orthotopic mouse models of triple-negative breast cancer. J Mol Med (Berl) 92: 151-164, 2014.

12. Yoon C, Chang KK, Lee JH, Tap WD, Hart CP, Simon MC, Yoon SS: Multimodal targeting of tumor vasculature and cancer stem like cells in sarcomas with VEGF A inhibition, HIF $1 \alpha$ inhibition, and hypoxia activated chemotherapy. Oncotarget 7: 42844-428582016.

13. Cui CP, Wong CC, Kai AK, Ho DW, Lau EY, Tsui YM, Chan LK, Cheung TT, Chok KS, Chan ACY, et al: SENP1 promotes hypoxia-induced cancer stemness by HIF-1 $\alpha$ deSUMOylation and SENP1/HIF-1 $\alpha$ positive feedback loop. Gut 66: 2149-2159, 2017.

14. Han X, Wang XL, Li Q, Dong XX, Zhang JS and Yan QC: HIF-1 $\alpha$ SUMOylation affects the stability and transcriptional activity of HIF-1 $\alpha$ in human lens epithelial cells. Graefes Arch Clin Exp Ophthalmol 253: 1279-1290, 2015.

15. Tahmasebi S, Ghorbani M, Savage P, Gocevski G and Yang XJ: The SUMO conjugating enzyme Ubc9 is required for inducing and maintaining stem cell pluripotency. Stem Cells 32: 1012-1020, 2014. 
16. Wu Y, Guo Z, Wu H, Wang X, Yang L, Shi X, Du J, Tang B, $\mathrm{Li} \mathrm{W}$, Yang L, et al: SUMOylation represses Nanog expression via modulating transcription factors Oct4 and Sox2. PLoS One 7: e39606, 2012.

17. Han ZJ, Feng YH, Gu BH, Li YM and Chen H: The post-translational modification, SUMOylation, and cancer (Review). Int J Oncol 52: 1081-1094, 2018. (Review).

18. Gupta KJ, Kolbert Z, Durner J, Lindermayr C, Corpas FJ, Brouquisse R,BarrosoJB,Umbreen S,PalmaJM,HancockJT, et al: Regulating the regulator: Nitric oxide control of post-translational modifications. New Phytol: Apr 27, 2020 (Epub ahead of print).

19. Li R, Wei J, Jiang C, Liu D, Deng L, Zhang K and Wang P: Akt SUMOylation regulates cell proliferation and tumorigenesis. Cancer Res 73: 5742-5753, 2013.

20. Ni P, Xu H, Chen C, Wang J, Liu X, Hu Y, Fan Q, Hou Z and $\mathrm{Lu}$ Y: Serum starvation induces DRAM expression in liver cancer cells via histone modifications within its promoter locus. PLoS One 7: e50502, 2012.

21. Polderman JA, Farhang-Razi V, Van Dieren S, Kranke P, DeVries JH, Hollmann MW, Preckel B and Hermanides J: Adverse side effects of dexamethasone in surgical patients. Cochrane Database Syst Rev 8: CD011940, 2018.

22. Tang H, Jin Y, Jin S, Tan Z, Peng Z and Kuang Y: Arsenite inhibits the function of $\mathrm{CD} 133^{+} \mathrm{CD} 13^{+}$liver cancer stem cells by reducing PML and Oct4 protein expression. Tumour Biol 37: 14103-14115, 2016.

23. Luo T, Wang L, Wu P, Gong W, Chen W, Zhao H and Zheng Z: Downregulated vimentin and upregulated E-cadherin in T1 stage non-small-cell lung cancer: Does it suggest a mesenchymal-epithelial transition? Neoplasma 64: 693-699, 2017.

24. Zilio N, Eifler-Olivi K and Ulrich HD: Functions of SUMO in the Maintenance of Genome Stability. Adv Exp Med Biol 963: $51-87,2017$

25. Zhao X: SUMO-mediated regulation of nuclear functions and signaling processes. Mol Cell 71: 409-418, 2018

26. Pichler A, Fatouros C, Lee H and Eisenhardt N: SUMO conjugation - a mechanistic view. Biomol Concepts 8: 13-36, 2017.

27. Wang L, Zhang T, Fang M, Shen N, Wang D, Teng J, Fu B, $\mathrm{X}$ ie $\mathrm{H}$, Hong $\mathrm{Q}$ and Lin $\mathrm{H}$ : Podocytes protect glomerular endothelial cells from hypoxic injury via deSUMOylation of HIF-1 $\alpha$ signaling. Int J Biochem Cell Biol 58: 17-27, 2015.

28. Gupta P, Ho PC, Huq MM, Ha SG, Park SW, Khan AA, Tsai NP and Wei LN: Retinoic acid-stimulated sequential phosphorylation, PML recruitment, and SUMOylation of nuclear receptor TR2 to suppress Oct4 expression. Proc Natl Acad Sci USA 105 11424-11429, 2008.

29. Parikh ND, Fu S, Rao H, Yang M, Li Y, Powell C, Wu E, Lin A, Xing B, Wei L, et al: Risk assessment of hepatocellular carcinoma in patients with hepatitis $\mathrm{C}$ in China and the USA. Dig Dis Sci 62: 3243-3253, 2017.

30. Mak LY, Cruz-Ramón V, Chinchilla-López P, Torres HA, LoConte NK, Rice JP, Foxhall LE, Sturgis EM, Merrill JK, Bailey $\mathrm{HH}$, et al: Global epidemiology, prevention, and management of hepatocellular carcinoma. Am Soc Clin Oncol Educ Book 38: 262-279, 2018.
31. Pinna AD, Yang T, Mazzaferro V, De Carlis L, Zhou J, Roayaie S, Shen F, Sposito C, Cescon M, Di Sandro S, et al: Liver transplantation and hepatic resection can achieve cure for hepatocellular carcinoma. Ann Surg 268: 868-875, 2018

32. Akoad ME and Pomfret EA: Surgical resection and liver transplantation for hepatocellular carcinoma. Clin Liver Dis 19: 381-399, 2015.

33. Fillat C, Carrió M, Cascante A and Sangro B: Suicide gene therapy mediated by the Herpes Simplex virus thymidine kinase gene/Ganciclovir system: Fifteen years of application. Curr Gene Ther 3: 13-26, 2003.

34. Zhang JH, Wan MX, Pan BR and Yu B: Cytotoxicity of HSVtk and hrTNF-alpha fusion genes with IRES in treatment of gastric cancer. Cancer Biol Ther 3: 1075-1080, 2004.

35. Parada C, Hernández Losa J, Guinea J, Sánchez-Arévalo V, Fernández Soria V, Alvarez-Vallina L, Sánchez-Prieto R and Ramón y Cajal S: Adenovirus E1a protein enhances the cytotoxic effects of the herpes thymidine kinase-ganciclovir system. Cancer Gene Ther 10: 152-160, 2003.

36. Shang F, Liu M, Li B, Zhang X, Sheng Y, Liu S, Han J, Li H and Xiu R: The anti-angiogenic effect of dexamethasone in a murine hepatocellular carcinoma model by augmentation of gluconeogenesis pathway in malignant cells. Cancer Chemother Pharmacol 77: 1087-1096, 2016.

37. Ogasawara S, Chiba T, Ooka Y, Kanogawa N, Motoyama T, Suzuki E, Tawada A, Nagai K, Nakagawa T, Sugawara T, et al: A randomized placebo-controlled trial of prophylactic dexamethasone for transcatheter arterial chemoembolization. Hepatology 67: 575-585, 2018.

38. Yang H, Seon J, Sung PS, Oh JS, Lee HL, Jang B, Chun HJ, Jang JW, Bae SH, Choi JY and Yoon SK: Dexamethasone Prophylaxis to Alleviate Postembolization Syndrome after Transarterial Chemoembolization for Hepatocellular Carcinoma: A Randomized, Double Blinded, Placebo Controlled Study. J Vasc Interv Radiol 28: 1503-1511.e2, 2017.

39. Tang YA, Chen YF, Bao Y, Mahara S, Yatim SMJM, Oguz G, Lee PL, Feng M, Cai Y, Tan EY, et al: Hypoxic tumor microenvironment activates GLI 2 via HIF-1 $\alpha$ and TGF- $\beta 2$ to promote chemoresistance in colorectal cancer. Proc Natl Acad Sci USA 115: E5990-E5999, 2018.

40. Covello KL, Kehler J, Yu H, Gordan JD, Arsham AM, Hu CJ, Labosky PA, Simon MC and Keith B: HIF-2alpha regulates Oct-4: Effects of hypoxia on stem cell function, embryonic development, and tumor growth. Genes Dev 20: 557-570, 2006.

41. Yuan L, Jiang ZM, Chen XH, Bian XY, Li YX, Ma XF and Liu XZ: Hypoxia inducible factor- $1 \alpha$ deSUMOylation reduces the stemness maintenance ability of endometrial cancer stem cell and increases its chemosensitivity. Zhonghua Yi Xue Za Zhi 97: 3579-3582, 2017 (In Chinese).

42. Liebelt $F$ and Vertegaal AC: Ubiquitin-dependent and independent roles of SUMO in proteostasis. Am J Physiol Cell Physiol 311: C284-C296, 2016.

This work is licensed under a Creative Commons Attribution-NonCommercial-NoDerivatives 4.0 International (CC BY-NC-ND 4.0) License. 